\title{
LA HUBRIS EN GRECIA ANTIGÜA: EN TORNO AL MAL EN HOMERO, PLATON Y ARISTÓTELES
}

\author{
Hubris in Ancient Greece: On Evil in Homer, Plato and Aristotle
}

Lic. Jean Luis Arana Alencastre*

Recepeción: 08-01-2018

Aceptación: 30-04-2018

\begin{abstract}
RESUMEN
El presente trabajo trata de mostrar someramente el concepto de hubris en la Grecia Antigua y en sus principales exponentes. De manera que se pueda entender en nuestro tiempo la importancia del mismo y las advertencias que sugieren sus consecuencias. Veremos que la hubris en Homero se muestra en la cólera de Aquiles; en los poetas, en la naturaleza de la soberbia extrema; en Platón, en el excesivo deseo por el placer; y en Aristóteles, en el ensañamiento hacia el otro, por el puro placer de verlo sufrir.

Así, indagaremos sobre el mal que descubrieron los griegos en la naturaleza humana, y veremos que, aunque sepultada en el pasado por el olvido de la memoria del hombre moderno, la soberbia, el exceso, en suma, la hubris está y puede hacerse presente en los actos del hombre, aunque ya no la reconozcamos, tal vez, como tal.
\end{abstract}

\section{PALABRAS CLAVE}

Hubris, exceso, cólera, mal, coraje, venganza, placer, ensañamiento, humillación.

\begin{abstract}
The present work aims to show in a simple way the concept of hubris in ancient Greece through some of its most representative authors. It seeks to understand the importance of this notion nowadays and the warnings its consequences present to us. We will see that hubris makes an appearance in Homer, in the rage of Achilles; in the poets, in the nature of extreme pride; in Plato, in the excessive desire for pleasure; and in Aristotle, in the cruelty towards another for the sole pleasure of seeing him suffer.

To this end, we will examine the evil that the Greeks discovered in human nature, and we will see that, although buried in oblivion by the modern man, hubris in the form of pride and excess can be present in human acts, even if we can no longer recognize it.
\end{abstract}

\section{KEY WORDS}

Hubris, excess, rage, evil, courage, vengeance, pleasure, cruelty, humiliation.

\footnotetext{
* Docente en la UPC, Docente en el ISET, Pre-Docente en la PUCP: sobrio64@hotmail.com, a20007201@ pucp.edu.pe
} 
En el presente artículo quisiera abordar de manera sucinta, a modo del trazo de un pincel, el tema de la hubris en Grecia antigua, principalmente en Homero, en las tragedias, en Platón y en Aristóteles. Considero su reflexión necesaria para comprender de qué trata el problema del mal que supone ella, y con ello profundizar en el conocimiento del ser humano y de su actuar, y así, poder decir algo desde la antigüedad para la reflexión ética de nuestro tiempo.

Para los antiguos griegos, el concepto de hubris representaba el mayor delito que un griego podía cometer; pues suponía la insolencia extrema contra los dioses y contra los hombres. Y ello era: el violento sobrepasar los límites siendo insolente en el triunfo ${ }^{1}$.

Y es importante reflexionar sobre ello en nuestros días, pues vemos que en casi todos los ámbitos en los que el ser humano se desenvuelve existe una suerte de exceso que, tal vez, está socavando la armonía y desordenando la vida en comunidad.

\section{En Homero}

¿Qué significa el sobrepasar los límites? Para responder primero veamos a la hubris en la mayor y primera obra literaria que forjó de muchas maneras el mundo occidental: la Ilíada. En ella, Homero retrata de manera magistral lo que podría ser la tragedia del más grande guerrero de todos los tiempos: Aquiles, el de los pies ligeros. Dicha tragedia surge por su cólera, la cual es guiada e incitada por su hubris y nos muestra aquella, por medio del poeta, el precio de esta: el sufrimiento.
Recordemos, entonces, cómo comienza la Íliada:

La cólera canta, oh diosa, del Pélida Aquiles,maldita, que causó a los aqueos incontables dolores, precipitó al Hades muchas valientes vidas de héroes y a ellos mismos los hizo presa para los perros... (Ilíada, Canto I, 1-5)

En estos primeros versos el Aedo ${ }^{2}$ le pide a la diosa ${ }^{3}$ que cante a través de él la cólera de Aquiles, el hijo de Peleo y de la diosa Tetis. De esa manera, se anuncia la trama de la obra: la hubris de Aquiles, la que es traducida en la cólera, lo posee tras enterarse de la muerte de Patroclo, su amante ${ }^{4}$.

Es Héctor, Hijo de Príamo y príncipe de Troya quien da muerte a Patroclo en una batalla violenta, en los siguientes versos vemos en nuestra imaginación gracias a las palabras qué sucedió:

Héctor, nada más ver al magnánimo Patroclo retrocediendo, herido por el agudo bronce,llegó cerca de él entre las filas, le hirió con la lanza en lo más bajo del ijar y le hundió el bronce de parte a parte. Retumbó al caer y causó gran pesar a la tropa de los aqueos (Ilíada, Canto XVI, 815-820)

Así murió Patroclo, y antes de morir el mismo vaticina la muerte de Héctor diciéndole:

Ya te has jactado ahora, Héctor, demasiado. Te han dado la victoria

\footnotetext{
1 W.G. BURGH, citado por Barclay W. Palabras griegas del nuevo testamento, 52:2002

2 Poeta griego que cantaba de memoria

3 En otras traducciones se prefiere Musa

4 La cólera de Aquiles es el punto central de la obra, la que causa la tragedia traducida en las muertes de tantos y finalmente en la destrucción de Troya.
} 
Zeus Crónida y Apolo, que me han doblegado fácilmente; pues ellos me han quitado las armas de los hombros... Tampoco tú vivirás mucho tiempo; próximos a ti ya acechan la muerte y el imperioso destino, Que te harán sucumbir a manos del intachable Aquiles Eácida (Ilíada, Canto XVI, 845-850)

Estas palabras de Patroclo predicen la muerte y el destino del héroe; pero; además, muestran como un anticipo la hubris de Aquiles al estar llenas de furia por ser amenazantes. Y es que, al recibir un daño, en este caso, el peor mal de todos, como Patroclo solemos disgustarnos con lo que causa dicho daño, en este caso con Héctor. La respuesta es desafiante y encolerizada. Odiamos todo aquello que hace un mal, tal vez, sin ver que nuestras mismas acciones nos pusieron en dicha situación o hubo muchos factores que desencadenaron aquellas nefastas consecuencias. Héctor defendía su tierra amada, los griegos la invadieron, Patroclo quiso ir a pelear, Helena se fue o la raptó Paris, etc. Sin embargo, solo vemos quizás aquello que inmediatamente nos daña y lo odiamos. En ese sentido, tal vez, nuestro odio está puesto en un lugar equivocado.

Ahora bien, la muerte de Patroclo es un mal que enardece a Aquiles por el amor que le tenía, entonces era un mal para Aquiles, para Patroclo y en fin para el ejército griego, pero pudo ser un bien para los troyanos que se defendían del ataque de los extranjeros. Así vemos además que no solo odiamos lo que nos parece malo inmediatamente sino aquello que puede ser bueno para otros.

Cuánta reflexión sobre estos dos puntos necesita el hombre contemporáneo que no se detiene a pensar en que su parecer no puede ser absoluto y acaparar para sí con ello todos los aspectos de la realidad. Esto es lo que le sucede a Aquiles, el de los pies ligeros, más adelante, al enterarse de la muerte de Patroclo:

Aquiles dio un pavoroso gemido, que su augusta madre escuchó sentada en los abismos del mar al lado de su anciano padre y la hizo exhalar un suspiro. Y las diosas se congregaron, todas las nereidas que estaban en el abismo del mar (Ilíada, Canto XVIII, 35-40)

Y cuando llega su madre a consolarlo Aquiles le dice con una pena que embarga:

iMadre mía! Cierto que el Olímpico me ha cumplido eso ${ }^{5}$. Mas ¿qué placer me reporta, cuando perecido mi compañero Patroclo, a quien apreciaba sobre todos mis camaradas, como a mi propia cabeza? Lo he perdido; Héctor lo ha matado y desnudado de la extraordinaria armadura, maravilla para la vista, bella, espléndido regalo que los dioses dieron a Peleo aquel día en que te llevaron al lecho de ese hombre mortal (Ilíada, Canto XVIII, 80-85)

La tristeza que se nota en las palabras de Aquiles solamente será reemplazada por su cólera, y poseído por ella lleno de hubris decide, entonces, ir a matar a Héctor:

Ahora iré en bucsa del matador de esa querida cabeza para mí, en busca de Héctor. Mi parca yo la acogeré gustoso cuando Zeus quiera traérmela y también los

5 Se le cumplió la promesa de Zeus, le recuerda su madre Tetis, a saber, que los hijos de los aqueos, privados de el quedarían indefensos y sufrirían desastrosas derrotas. 
demás dioses inmortales (Ilíada, Canto XVIII, 110-115)

Podemos ver de cierta manera a partir de estos versos que nos muestra Homero que la hubris es el exceso encolerizado que nace, en el caso de Aquiles, desde el profundo dolor de perder a su amante. Ese dolor no busca ya la justicia en la razón, es decir, en la reparación, ni la retribución siquiera del mismo dolor, ni en última instancia en la satisfacción de la venganza sino la destrucción total. Pues la cólera lo ha poseído y con ello enceguecido a partir de la apropiación personal de lo que se ve y luego cree como malo. Y este punto de vista, es lo que genera, tal vez, todo desentendimiento hacia la sensatez. Llama a la furia, pues solo lo que es personal importa.

En ese sentido, Aquiles estaba enceguecido, ya no pensaba, ya no temía ni siquiera a los dioses ni siquiera a su muerte. Es así que luego:

Aquiles atacó a los troyanos con la mente revestida de coraje, profiriendo pavorosos alaridos, y capturó primero a Iftión, el valeroso Otrintida, príncipe de numerosas huestes, a quien por obra de Ontrinteo, saqueador de ciudades (Ilíada, Canto XX, 380-385)

Podría parecer que el Pélida estaba poseído por la lyssa: la pasión temeraria que solos los dioses podían ser capaces de infundir en un hombre y que este con aquella desplegaba súbitamente la valentía del Olimpo en batalla. Sin embargo, el coraje no era realmente fruto de la valentía inspirada por la lyssa, sino era la cólera nacida de la hubris. Por tanto, no era desde el corazón encendido de la inspiración de un dios el coraje de Aquiles sino desde su corazón ensombrecido y enardecido por su cólera, su sed de venganza, y mucho más que eso, por su hubris.

Y es fácil confundirlas, sobre todo ahora, en nuestro tiempo, donde es justificable una violencia a partir de un parecer estar retribuyendo un mal, y hasta el mal por el mal es justificado. Pero no es lo mismo, luchar por lo justo que ajusticiar injustamente y violentamente lo aparentemente malo ${ }^{6}$.

Era de esperarse que Aquiles, el de los pies ligeros, obtenga la victoria, más aún peleando sin piedad. Es así que le clavó la pica a Iftión Otrintida y al caer este el divino Aquiles exclamó triunfante con las palabras que solo podrían pronunciarse desde la oscuridad:

iYaces, Ontrintida, el más temible de todos los hombres! aquí has hallado la muerte y lejos está tu lugar de nacimiento, junto a la laguna Gigea, donde está el coto de tus ancestros a orillas del hilo, rico en peces, y del turbulento Hermo (Ilíada, Canto XVIII, 390)

6 En nuestros días, vivimos una suerte de violencia extrema, exacerbada que creo que fundamente es este punto: nos creemos capaces de usar la violencia, confundiéndola con valentía para castigar realmente, pero diciendo que se desea lo justo. Por qué entonces un hombre quemaría a una mujer que supuestamente desea sino es por la cólera que se engaña con la máscara de la justicia, por qué un hombre mataría a su esposa e hijos que supuestamente ama, por qué una mujer aniquilaría a su amante si no es por una suerte de pensamiento que de alguna manera se justifica devolviendo un mal por aquello que se creyó que fue un mal. O vengándose castigando con un mal aquello que hizo daño, pero que tal vez fue involuntario o voluntario. El tema es que no interesa ahora ya si fue un mal involuntario, sino que solo interesa devolver el mal, vengarse, pero con la bandera de la justicia a su lado. ¿Es lícito devolver mal por mal? ¿La justicia se muestra en la venganza? En principio suena contradictorio, pues no podría reclamar justicia cometiendo una injusticia. Y, sin embargo, vemos que la hubris posibilita eso mismo. Aquello que la razón nos muestra, la hubris lo cubre, lo oculta en la oscuridad de su pasión. 
Le restriega su muerte, y la celebra. Recuerda su lugar de nacimiento, y pareciera que en vez de tristeza por encontrarse lejos de su lugar de nacimiento, siente no alegría, pero algo parecido a una cierta satisfacción por ello. ¿Aquiles no recuerda que re repente Iftión es el amado de alguien? ¿No se da cuenta que lo mismo que hizo Héctor con Patroclo, lo está haciendo él con el Ontríntida? Ésta es la ceguera de la cual se hablaba. Aquiles es incapaz de ver sus mismas acciones, no puede y no quiere pensar más allá de sí mismo. Ese ensimismamiento bien podría llamarse también un excesivo egocentrismo, pues no importa nada más que aquello que a uno le importa. Y no solo ello, sino que las palabras de Aquiles reflejan humillación y jactancia, palabras que están muy lejos de ser pronunciadas por aquel que lucha por algo justo.

Finalmente, cuando Aquiles va en busca de Héctor, el príncipe de Troya, se verá la infinita vastedad de la oscuridad de la hubris. Tras vencerlo, pues, el mismo Aquiles, con sus palabras guiadas por su cólera nos hace entrar y mirar esa oscuridad ilimitada:

Desfallecido, le dijo Héctor, el de tremolante penacho: "iTe lo suplico por tu vida, tus rodillas y tus padres! no dejes a los perros devorarme junto a las naves de los aqueos; en lugar de eso, acepta bronce y oro en abundancia, regalos que te darán mi padre y mi augusta madre, y devuelve mi cuerpo a casa, para que al morir del fuego me hagan participe los troyanos y las esposas de los troyanos" mirándolo con torva faz, replicó Aquiles, de pies ligeros: "No implores, perro, invocando mis rodillas y a mis padres.
iOjalá que a mí mismo el furor y el ánimo me indujeran a despedazarte y a comer cruda tu carne por tus fechorías! tan cierto es eso como que no hay quien libre tu cabeza de los perros, ni, aunque el rescate diez veces o veinte veces me lo traigan y lo pesen aquí y además prometan otro tanto, y ni siquiera, aunque mandara pagar tu peso en oro Príamo Dardánida. Ni aun así tu augusta madre depositará en el lecho el cadáver de quien ella parió llorarlo. Los perros y las aves de rapiña se repartirán entero tu cuerpo." (Ilíada, Canto XXII 335 - 350)

Qué palabras tan sombrías y duras las que profiere Aquiles. Pareciera que en estado de hubris Aquiles es poseído por algo que no puede controlar, que ya no es él mismo quien incentiva sus actos. Y éstos habrían dejado de ser ya verdaderamente libres con la convicción de que existe un derecho de actuar así. ¿Es justa tanta cólera? ¿Es posible erigirse como si uno fuera juez supremo entre la vida y la muerte? Y, sin embargo, muchas veces, en nuestro tiempo, podríamos decir que lo hacemos. No es acaso aquellos ensañados asesinatos que vemos todos los días en las noticias que nos hacen preguntarnos ¿¿¿Por qué?! ¿Era necesario tal extremo? La hubris no es algo que haya dejado de existir o que solo poseían los griegos, es algo que descubrieron ellos en la naturaleza del ser humano, un mal entendido desde el exceso que arremete de manera extrema con lo que pensábamos era un límite.

El límite parece poner en quietud nuestro ímpetu, pero la hubris no reconoce aquello, no se satisface con nada. Como lo vemos con Aquiles, pues no satisfecho con lo que había hecho, El de los pies ligeros invadido por la hubris, desafió hasta 
a los mismos dioses y en su cólera creyó poder aceptar cualquier juicio de ellos mostrándolo con estas palabras:

Ya moribundo, le dijo Héctor, el de tremolante penacho: "Bien te conozco con sólo mirarte que tienes en las entrañas. Cuídate ahora de que no me convierta en motivo de la cólera de los dioses contra ti el día en que Paris y Febo Apolo te hagan perecer, a pesar de tu valor, en las puertas Esceas." Apenas hablar así, el cumplimiento de la muerte lo cubrió. El aliento vital voló de la boca y marchó a la morada de Hades, llorando su hado y abandonando la virilidad y la juventud. Ya estaba muerto cuando dijo Aquiles, de la casta de Zeus: "iMuere! Mi parca yo la acogeré gustoso cuando Zeus quiera traérmela y también los demás dioses inmortales (Ilíada, Canto XXII 355 - 365)

Aquiles no teme morir ni teme el juicio de Zeus. La hubris ha hecho de él un hombre soberbio, sin piedad. Lo ha convertido en algo monstruoso: en la mismísima Furia sin sentido y que; sin embargo, jamás hallará tranquilidad ni satisfacción. ¿No es acaso aquella soberbia extrema que vemos en los asesinos de nuestro tiempo, en los corruptos, en los criminales, y hasta en aquellos que no son tocados por la compasión al ver a la gente morir de hambre y matarse en guerras sin sentido? ¿No es acaso aquello que vemos cuando nadie es capaz de reconocer el mal cometido, sino que lo justifica? Ciertamente Aquiles no. Y no solo ello, sino que, además, no contento con eso Aquiles, El de los pies ligeros:

...le quitó de los hombros las armas ensangrentadas. Los hijos de los aqueos acudieron corriendo y quedaron admirados de la talla y de la envidiable belleza de Héctor; y nadie hubo que se presentara y no lo hiriera. Y así decía cada uno, mirando al que tenía próximo: "iQué sorpresa! iAhora sí que es Héctor mucho más blando de tocar que cuando prendió las naves con el voraz fuego." (Ilíada, Canto XXII 365 - 375) le taladró por detrás los tendones de ambos pies desde el tobillo al talón, enhebró correas de bovina piel que ató a la caja del carro y dejó que la cabeza arrastrara. Montó en la caja del carro, recogió la ilustre armadura, los fustigó para arrearlos, y los dos de grado echaron a volar. Gran polvareda se levantó del cadáver arrastrado; los cabellos oscuros se esparcían, y la cabeza entera en el polvo yací, antes encantadora. Zeus entonces a sus enemigos había concedido que lo ultrajaran en su propia patria. (Ilíada, Canto XXII 395)

¿Era necesario tanto? ¿Por qué Aquiles no se calmó, por qué no paró? No satisfecho con haber matado a Héctor sigue maltratando y violentando su cadáver, incluso frente a su familia y a sus compatriotas. ¿Por qué tanto? ¿Existe alguna razón para ello? No. Aquiles no encontraba límite. Y es allí donde la ética debe entender el límite, pues es en ese momento, en donde ya no hay sentido ni razón, que se debe decir hasta aquí es suficiente. ¿Cuántas veces nosotros nos hemos dejado llevar por esa furia que desconoce los límites? ¿Qué ni siquiera volteamos a preguntarnos sobre ellos? Homero nos muestra que es aquí donde se debe establecer una línea demarcada por el comienzo del sin sentido. 
Aquiles, por más humillación que hiciera, sabía que no iba a traer de vuelta a Patroclo, era testigo del sufrimiento de los padres, de la esposa y del hermano de Héctor, Paris, y, a pesar de todo ello, no paraba con la humillación. Así es que se muestra el exceso no conociendo ni reconociendo límites. La hubris; por tanto, es el abandono al exceso infinito al mismo sufrimiento sin fin. Pues Aquiles en su mismo accionar sigue alimentando esa furia irracional. No es satisfacción lo que la hubris ofrece sino más bien sufrimiento. Y eso, quizás lo hemos olvidado. Cuando pedimos venganza, cuando arremetemos contra aquel que hace daño, solo queremos devolver el daño olvidando que abandonarnos en la sed de venganza que aparenta la retribución solo nos generará más sufrimiento.

¿Cómo regresar desde ese estado ilimitado a la cordura? ¿Desde lo irracional a lo racional? El arrebato violento de la hubris parece no conocer tregua. No busca nada, nada la satisface. El abandonarse a ese exceso es realmente perderse, abandonándose a no tener límites.

Es Príamo, Rey de Troya; sin embargo, que muestra algo nuevo, al parecer trae de vuelta a divino guerrero sufriente y cegado por su cólera. Ya en el cansancio, luego del arrebato pasional y de la batalla. Príamo va al encuentro de Aquiles y con estas palabras le trata de expresar un sufrimiento tan igual o mayor al que Aquiles siente:

iAcuérdate de tu padre, Aquiles, semejante a los dioses, que tiene mi misma edad y está en el funesto umbral de la vejez! (Ilíada, Canto XXIV 485 2-3)

La similitud, que aparece a través del recuerdo del padre de Aquiles, con Príamo evoca una suerte de compasión en el hábil guerrero. Lo que genera que Homero la exprese con estas íntimas palabras,

El recuerdo hacía llorar a ambos: el uno al homicida Héctor lloraba sin pausa, postrado ante los pies de Aquiles; y Aquiles lloraba por su propio padre y a veces también por Patroclo; y los gemidos se elevaban en la estancia. (Ilíada, Canto XXIV 505-510)

Es una escena digna de imaginar y absolutamente conmovedora. Dos hombres sufriendo y consolándose al punto de verse como iguales e incluso de tener una relación filial. Uno llorando por su hijo muerto; el otro, por su amante. Qué es lo que le muestra al Pélida Príamo cuando va a rogar por su hijo. Me atrevería a decir que es la compasión a través de la visión de la semejanza entre todos los hombres. Tal vez sería suficiente para nuestros días esa sola idea: comprender que, al ser todos semejantes, debemos de tratarnos y considerarnos como tales. Cuántos sufrimientos nos ahorraríamos si tan solo viéramos la fuerza de esa noción.

Así entonces, la hubris es un tema muy importante y central en la Ilíada y por ende en Grecia antigua. Para Homero la cólera desmesurada es la que lleva a Aquiles y a los aqueos a su destino fatal. Es el detonante del desenlace trágico: la destrucción del propio ser que supone sufrimiento.

\section{En las tragedias}

Ahora bien, en las tragedias clásicas, se muestra qué implica ese sobrepasar los límites que caracteriza a la hubris y qué significa ser insolente en un sentido teológico. 
Esquilo, por ejemplo, dice: "Ciertamente la hubris es la hija del ateísmo" (Esquilo, Euménides 533) y "En verdad, Zeus es castigador del orgullo presuntuoso, y corrige con mano dura. Por tanto, ahora que mi hijo ha sido advertido por la voz de Dios para que siga la prudencia, os ruego que lo instruyáis, con admoniciones razonables, para que deje de atraer sobre sí el castigo de los cielos por su jactanciosa temeridad" (Esquilo, persas, 827-831). Y el mismo Darío, comenta sobre su hijo Jerjes que "Siendo mortal, en su desatino pensó que llegaría a ser señor hasta de los mismos dioses" (Esquilo, persas, 794); pues "Él abrigó la esperanza de sujetar con cadenas, como a un esclavo, al sagrado, fluyente Helesponto, al Bósforo, acuífera corriente de un dios" (Esquilo, persas, 745$)^{7}$. Y Esquilo, juzgándolo dice: "Cuando se es mortal no hay que abrigar pensamientos más allá de la propia medida" (Esquilo, persas, 820). Además, "Un viejo hubris siempre engendra otro hubris que añadir a las calamidades humanas" (Esquilo, Agamenón 760). Por tanto, el no saber obrar con prudencia significa sobrepasar los límites que los dioses han establecido para los hombres, y ello desencadena, las más terribles desgracias. No porque los dioses castiguen a los hombres sino porque se desconoce todo límite de manera absoluta lo que deviene en una especie de endiosamiento personal. Si no hay límites ni dioses que los establezcan, entonces todo es posible. Esta posibilidad puede verse tanto en un sentido positivo como en uno negativo; tomándola como una oportunidad de construir y crear, por un lado, y como la permisividad total, por el otro. En el caso de la hubris, evidentemente desconocerá los límites no para la armonía sino al contrario para la destrucción.

Sófocles también escribió sobre la soberbia desmedida y dijo que "Hubris engendra un tirano" (Sófocles, Edipo Tirano, 873) y ¿quién quiere a los tiranos? ¿Acaso no es debido a la hubris que engendra odio y repulsión por parte de los otros?

Asimismo, el gran Eurípides dijo "Si tienes más de bueno que de malo, cuando seas hombre obrarás rectamente y bien. Pero, querido niño, abstente de malos pensamientos; apártate del hubris, ese orgullo presuntuoso; pues desear ser más grande que Dios no es otra cosa que hubris" (Eurípides, Hipólito, 472-474).

Entonces, podemos ver que los poetas griegos pensaban que cuando los hombres se olvidaban de su mortalidad, cuando pensaban que estaban sobre el bien y el mal era cuando, ciegos por causa de la hubris, se alzaban contra dioses y hombres, e insolentes dejaban la razón y la mesura.

\section{En Platón}

Asimismo, no debía faltar que el gran Platón, en su obra central La República, hable principalmente de la Justicia, y con ella de la hubris y de sus terribles consecuencias cuando esta posee al gobernante convirtiéndolo en tirano.

Es en el Libro III, donde critica a los poetas diciendo que deben cuidarse de sus palabras en vistas a una buena educación. Y para ello, por supuesto, es necesaria la moderación, virtud contraria a la hubris, que debe de ser debidamente mandada por los gobernadores a la multitud.

7 Herodoto cuenta que Jerjes se enciendió en ira porque el puente que había construido para cruzar el Bósforo y llegar a Tracia fue destruido por una tormenta. Y por ello, mandó cortarles las cabezas a los ingenieros, azotar al Hlsponto en castigo y, luego, lanzó improperios contra el mar y dijo: "Entiéndelo bien, y brama por ello; que el Rey Jerjes, quieras o no, pasará sobre ti" (Herodoto, Historia, VII, 35). 
Por ello, un gobernante no podría estar ni mostrarse a los ciudadanos "atontado por el vino, poseedor de ojos de perro y de un corazón de ciervo" (República, 389 e). Y de ello se sigue que no está bien que la voluptuosidad del exceso en las comidas, o en el sexo, en suma, en el placer corporal, sea mostrada en los versos de los poetas. Como cuando Homero canta que:

Al lado están las mesas abundantes, en pan y carne, mientras el escanciador saca el vino de la crátera, lo lleva y lo vierte en las copas (República, 390 a)

Y mucho menos dichas por los gobernantes, pues darían licencia con ello al libertinaje. Pues, para Platón, el darle tal lugar al placer corporal, que es irracional, hace parecer que las cosas más bellas son aquellas convenientes al exceso (hubris).

Platón quiere decir que el placer no es el mejor bien que uno puede poseer en la vida y no es lo más digno de alcanzar. Es decir, el destino más lamentable no es morir de hambre sino cometer injusticia. Esto quiere decir actuar de forma irracional deseando únicamente los placeres sensuales. En nuestra era, vemos que podemos darles rienda suelta a nuestros deseos de placer y disfrute sensorial casi ilimitadamente. Incluso existen lugares en donde ofrecen justamente aquello: la ilusión de comer, beber y disfrutar casi ilimitadamente por una modesta suma monetaria. La promesa de la felicidad traducida en el placer es lo que ahora la publicidad de muchos centros comerciales, restaurantes, clubes nocturnos, agencias de viajes, hoteles, etc. nos venden. Y no solo ello, sino que en nuestras mismas relaciones interpersonales colocamos al placer como la meta de aquellas. Poniendo el agrado o el surgimiento de emociones como criterios para estimar a una persona. Es muy grave lo que ha ocasionado el olvido de la hubris en nuestro tiempo. Y es Platón quien nos recuerda que el placer es un bien, pero no puede ser tomado como el mayor de todos ni como el Bien mismo.

Por ello, en cambio, dirá que hay que escuchar las palabras del poeta que reflejan la moderación y la mesura, además de la fortaleza del alma cuando dice:

Golpeándose el pecho, increpó a su corazón con estas palabras: Sopórtalo, corazón; ya otra vez afrontaste algo más horrible (República, 390 d)

Platón, así, por boca de Sócrates trata de hacer ver a Glaucón y a los demás que el excesivo placer corporal nada tiene que ver con la moderación ni con las virtudes como la templanza.

...el verdadero amor consiste por naturaleza en amar de forma moderada y armoniosa lo ordenado y bello (República, 403 a)

Las virtudes como vía de la buena vida es precisamente lo que hemos olvidado, además. Pues ahora, ya no interesa moderarse ni ser templado con respecto a nuestros placeres sensuales sino, más bien, es loable y necesario para alcanzar la felicidad. Cosa que sería imposible además para los griegos, pues la felicidad no era algo que se alcanzaba sino más bien era la buena vida a través de la práctica de las virtudes.

Platón en su obra el Protágoras señala a modo de síntesis la definición de templanza y hubris: 
Cuando la opinión conquista, y por la ayuda de la razón, nos conduce a lo mejor, el principio conquistador es llamado templanza (sophrosune); pero cuando el deseo, que carece de razón, nos gobierna, y nos arrastra al placer, ese poder de desgobierno es llamado hubris (Protágoras, 238a).

Es decir, en Platón, cuando el hombre es cegado por la pasión y no escucha a la razón comete hubris. Pero cuando su deseo es debidamente acompañado por el conocimiento y por la razón, se alcanzarán aquellos placeres dignos, pues los dicta la sabiduría. Esto "dado que siguen a la verdad, llegarán a los placeres más verdaderos, en la medida que esto les es posible, además de los placeres que les son apropiados, si es que lo mejor para cada cosa es también lo más apropiado" (República, 586 e). Así, lo que más se aleja de la razón son los apetitos eróticos y tiránicos, los cuales distan mucho de ser reales, verdaderos y ordenados. Por tanto, el tirano, así, es aquel que estará más alejado del placer que le es propio y verdadero. De esa manera, finalmente, vemos que en Platón la hubris está orientada hacia los placeres excesivos del cuerpo, alejados de la razón.

\section{En Aristóteles}

Aristóteles, por su parte, vio que la hubris era algo fundamentalmente perverso y mórbido (Aristóteles, Ética a Nicómaco, 1148b 30). Y aquel que desprecia a los otros (Aristóteles, Ética a Nicómaco, $1149 b$ 22) insultándolos deliberadamente comete hubris (Aristóteles, Ética a Nicómaco, 1125a 9). Así, en un sentido ético, si alguien era sujeto de hubris lo manifestaría con sus semejantes. Pero, además, ese desprecio genera odio y rencor (Aristóteles, Ética a Nicómaco, 1149 a 32), de manera que el poseído por la hubris siente placer al ver el sufrimiento ajeno (Aristóteles, Ética a Nicómaco, $1129 b$ 22). Lo que significa, entonces, el dañar por el dañar y siempre implica la humillación deliberada de la persona afectada.

Es por todo ello que la hubris era lo más cruel que podía un griego hacer en contra de otro. Aristóteles lo expresa como sigue:

También quien ultraja menosprecia, pues el ultraje es hacer o decir aquello de lo que la víctima se avergüenza, sin ánimo de que le ocurra nada más de lo que le ocurrió, sino para disfrutar de ello. Y es que los que toman represalias no ultrajan sino castigan. La razón del placer que sienten quienes ultrajan es que creen que al hacer daño son superiores al otro (Aristóteles, Retórica, 1378 b).

Así, la hubris era considerada algo malo siendo la más cruel de las faltas. No sólo era ser esclavo de las pasiones, como decía Platón, sino que, además de ello, era hacer sufrir por el sufrimiento mismo, como lo vio Aristóteles. Y esto era un acto gratuito de maldad porque no buscaba algo más allá del ver sufrir y regocijarse en ello.

Vemos así que la hubris para Aristóteles no es ira simplemente ni solamente deseo encolerizado de venganza. Pues la ira no es premeditada; un hombre se enciende en ira porque no puede evitarlo. Y la venganza se toma con la clara intención de restituirse algo; la venganza es por amor al desquite, y en último caso, a un concepto particular de justicia. Pero la hubris, la extrema insolencia, es el espíritu que hiere y después retrocede para ver a su víctima convulsionarse. Es herir por amor a herir y 
siempre implica la humillación deliberada de la persona que injuria. Es el placer por el sufrimiento del otro.

En ese sentido, actualmente, la crueldad y la humillación han tomado formas sutiles que se manifiestan en todos los medios y ámbitos en los que el ser humano actúa. Por citar un ejemplo: ahora el bullying también ha migrado a las redes sociales mostrando todo el poder que la humillación humana puede tener que, incluso muchos han tomado la decisión de acabar con sus vidas debido a ciberbullying. Pero incluso aquello sería un juego de niños si vemos el exceso en cuestiones mayores como el acoso sexual, la comercialización de seres humanos, los medios de comunicación y el rating que beben de la sangre y del sufrimiento de tantos, el morbo en los programas televisivos y en los espectáculos. La humillación vende, y eso es una de las cosas más perversas que ha podido generar el hombre: ya no es solo burlarse por el placer de ver sufrir a alguien como diría Aristóteles sino ahora es vender el sufrimiento para que otros se regocijen con él y sientan placer.

\section{Conclusión}

Es tal vez cuando el hombre se alza por encima de todo, creyéndose y olvidándose de los límites que se entra en un estado de hubris que lleva al thánatos de su ser. También es importante la reflexión sobre este tema, pues el mal entendido como hubris es una realidad ínsita en la naturaleza humana. Importante es comprender este concepto para una comprensión más amplia de la profundidad del ser humano, de su libertad y de los sufrimientos que lo aquejan. Solo en la profundidad de la reflexión podremos descubrir la necesidad de los límites y poder actuar de acuerdo con lo mejor y más excelente.
Homero no recuerda que es importante pensar sobre los límites y no dejarnos enceguecer por la cólera desmedida. Que la compasión en el semejante es clave para poder convivir en armonía y no sufrir. Platón nos dice que no podemos colocar al placer como el mayor y supremo bien, que ello nos llevará a la perdición de la sensualidad. Y Aristóteles nos advierte el peligro de beber del placer de sufrimiento, nos tuerce, nos lleva a un estado sin sentido, no de humanidad.

En el fondo resuena el mensaje del oráculo de Delfos: "Conócete a ti mismo", que implica conocer los propios límites, pero que, a la vez, se hace un llamado inmediato hacia el reconocimiento de lo divino, de lo absolutamente otro del cual no puedo disponer sino aceptar y asombrarme.

\section{REFERENCIAS}

Aristóteles (1985) Ética a NIcómaco. Trad. Mario Araujo y Julián Marias. Introducción. Julián Marías. Madrid: Centro de Estudios Constitucionales

Aristóteles (1998) Metafísica. Traducción: Valentín García Yebra. Madrid: Editorial Gredos.

Aristóteles (2009) Retórica. Madrid: Alianza Editorial. Madrid.

Aristóteles (2009) Poética. Madrid: Alianza Editorial.

Aristóteles (2009) Política. Madrid: Alianza Editorial.

Barclay W. (2002) Palabras griegas del nuevo testamento. Texas: Casa bautista de publicaciones. 
Homero (2000) Ilíada. Madrid: Biblioteca Clásica Gredos.

Platón (2009) Protágoras. Madrid: Alianza Editorial.

Platón (2009) Fedro. Madrid: Alianza Editorial.
Platón (2000) República. Madrid: Gredos.

Vernant, J. (1992) Los orígenes del pensamiento griego. Barcelona: Paidós Ibérica S.A. 